\title{
Community-based familial study of Helicobacter pylori infection among healthy Japanese Brazilians
}

\author{
Lucy S. Ito ${ }^{1}$, Sueli M. Oba-Shinjo ${ }^{1,2}$, Samuel K. Shinjo ${ }^{1,2}$, Miyuki Uno ${ }^{1,2}$, Suely K.N. Marie ${ }^{2}$, \\ and NobUYUKI HAMAJIMA ${ }^{3}$ \\ ${ }^{1}$ Japanese Brazilian Health Professional Volunteer Group, São Paulo, Brazil \\ ${ }^{2}$ Laboratory of Molecular Biology, Department of Neurology, School of Medicine, São Paulo University, São Paulo, Brazil \\ ${ }^{3}$ Department of Preventive Medicine/Biostatistics and Medical Decision Making, Nagoya University Graduate School of Medicine, Nagoya, \\ Japan
}

\begin{abstract}
Background. The present study of Helicobacter pylori infection was conducted in family units of Japanese Brazilians living in São Paulo city. The authors attempted to determine the seroprevalence of $\boldsymbol{H}$. pylori infection within family units of Japanese Brazilians and to identify risk factors associated with intrafamilial transmission.

Methods. The seroprevalence was determined in 1037 healthy and asymptomatic volunteer subjects aged 0-69 years (530 adults and 507 children) of 265 families. Demographic data and details of living conditions were obtained from each family.

Results. $\boldsymbol{H}$. pylori seropositive infection was found in $\mathbf{3 9 . 2} \%$ of the parents and $9.3 \%$ of the children. A reduced risk of $\boldsymbol{H}$. pylori infection was found for girls (odds ratio [OR] 0.45 ; 95\% confidence interval [CI], 0.23-0.86). The prevalence of infection was $3.5 \%$ for children with uninfected parents; $9.9 \%$ (OR, 2.51; 95\% CI, 0.95-6.61) for those with a seronegative mother and a seropositive father; $14.9 \%(\mathrm{OR}, 4.93$; $95 \% \mathrm{CI}$, 1.86-13.06) for those with a seropositive mother and a seronegative father; and $16.0 \%(O R, 5.29 ; 95 \%$ CI, 1.98-14.14) for those with seropositive parents. On multivariate analysis, the use of a pacifier, and mother's symptoms of nausea and vomiting were significantly associated with the risk of $\mathrm{H}$. pylori infection for children, and the child having her/his own room was significantly associated with a reduced risk. Income was not associated with $\boldsymbol{H}$. pylori infection in children and was inversely associated in parents.

Conclusion. The prevalence of $\boldsymbol{H}$. pylori infection in family units of Japanese Brazilians supports the hypothesis of a predominant role for mother-child transmission of $\boldsymbol{H}$. pylori infection, mainly through contact with regurgitated gastric juice in the mother's mouth.
\end{abstract}

Offprint request to: L.S. Ito

Center for Health Promotion and Disease Prevention, Rua Santa Madalena, 220/143B, São Paulo-SP, 01322-020, Brazil Received: November 7, 2005 / Accepted: May 14, 2006
Key words Helicobacter pylori · Japanese Brazilians · Children · Family $\cdot$ Serologic tests

\section{Introduction}

Infection with Helicobacter pylori in the stomach is highly associated with the development of gastritis and peptic ulcer disease [1,2]. Indeed, $H$. pylori infection has further been implicated in gastric carcinogenesis $[3,4]$. The prevalence of $H$. pylori infection varies widely by geographic area, ethnic group, socioeconomic status, and age [5-7]. Additionally, variations in age at acquisition of $H$. pylori can produce different effects in the gastric mucosa, resulting in the development of atrophic gastritis with a high risk of gastric cancer [8]. In developing countries, the majority of people become infected during childhood. Several studies have indicated that poor living condition are associated with the infection, with poor hygiene conditions [9], sharing a bed [10], and overcrowding being involved [11]. Investigations within families found that family members shared the same $H$. pylori strains, which indicates intrafamilial transmission [12-14]. Under natural circumstances, transmission could occur by the oral-oral or fecal-oral routes [15-17], but no strong evidence exists to support the idea that either route is primary [18].

The city of São Paulo, the third most populous city in the world, is located in the southern part of Brazil. The population is estimated to be 10.5 million and the number of Japanese descendants is estimated to be 400000 . Japanese Brazilians have maintained many aspects of Japanese culture; however, the geographical environment and lifestyle in Brazil are quite different from those in Japan. Our previous study with adult Japanese Brazilians showed that their overall $H$. pylori seropositivity was $48.1 \%$, with the pattern of the age-specific 
infection rate similar to that of Japanese in Japan [19]. The seropositivity rate was $61.8 \%$ among non-Japanese Brazilian blood donors [20]. On the other hand, gastric cancer mortality among Japanese Brazilians was reported to be as high as that among Japanese in Japan, which was more than $50 \%$ higher than that in nonJapanese Brazilians [21].

Concerning the intrafamilial transmission of $H$. pylori, population-based studies have been rarely reported. To design preventive measures against $H$. pylori transmission, it is important to understand where and how the infection occurs. The aim of the present study was to assess the seroprevalence of $H$. pylori infection within family units of Japanese Brazilians residing in São Paulo city, and to identify the risk factors associated with intrafamilial transmission.

\section{Subjects and methods}

\section{Location and subjects}

The study was carried out in São Paulo city, where 47 associations, named for each prefecture of Japan; Japanese cooperative societies; country clubs of Japanese Brazilians; Japanese language schools; and many other nonprofit Japanese associations have been found. The subjects of this study were volunteers with apparently good health conditions. The family units in this study were defined as husband, wife, and at least one nonadopted child aged between 0 and 19 years. The study required that both parents were Japanese or Japanese descendants whose family members all lived in the same household. A weekly announcement was made in local Japanese newspapers to inform the population about the study and the locations of the centers for sample and data collection. Daily radio announcements were also made on Japanese radio stations during the collection period. In total, 250 Japanese associations announced to their members details of participating in the study through a standardized letter informing them about the study aims, procedure, and confidentiality. Data were collected from January to March 2002. The collection of lifestyle data and blood was conducted at 23 different locations, including Japanese schools (kindergartens and elementary schools), social clubs, and cultural associations.

\section{Questionnaire}

After signing an informed consent form, both husband and wife were asked to complete a standard questionnaire on his/her demographic data and lifestyle, which was reviewed by a trained interviewer. Questions on the children were filled out by one of the parents, usually the mother. The parents signed the form instead of their children providing consent. The questionnaire included items on demographic data (sex, age, and birthplace), familial origin by prefecture of Japan, socioeconomic status (education, income, living conditions, and hygiene), personal and family disease history, smoking history, alcohol drinking, reproductive history, mouth hygiene, and medical history of the children. Weekly frequency of food intake was also questioned. Concerning their children, the following questions were asked: number of children; who responded to the questionnaire; demographic data (sex, age, and birthplace); weight, height, and birthplace (hospital, home, and others); place each child lived at age 0-5 years (type of house and area); who lived with and spent most of the time with the child from age 0 to 5 years; how the child was fed: who fed the child most often, period of breast feeding and use of a nursing bottle, frequency of premastication of food by parents, use of a pacifier (yes or no) and whether parents put the pacifier into their own mouths to "clean" it (never, less than ten times; ten times or more), child's sleeping arrangements (frequency of the child sleeping with the mother, whether the child had their own room before age 5 years, number of children sharing the room and who shared a room with the child for more than 1 month); whether the parents had symptoms of nausea or vomiting (never, rarely/year, frequently/months) when with the child at age $0-5$ years; whether the parents smoked or drank alcohol when with the child at age $0-5$ years; whether parents cleaned their child after going to the toilet (never, always; rarely); frequency of the child taking a shower with adults other than the parents; child's frequency of natural food intake (home made), and the intake of commercial baby food, fruits, and pickled vegetables; and origin of the child's drinking water. The number of families was 273 , representing 1054 subjects. Seventeen subjects from eight families who did not fulfill the family unit definition used in this study were excluded from the analysis. The remaining 1037 subjects (530 adults and 507 children) of 265 families of full Japanese ancestry were selected for the analysis. The samples were collected sequentially, without other inclusion or exclusion criteria, except for children with mental deficiency or chronic diseases. A 10-ml sample of venous blood was obtained from each family member. The blood samples were centrifuged and plasma was frozen at $-20^{\circ} \mathrm{C}$ according to a predetermined protocol.

\section{Laboratory tests}

An anti-H. pylori IgG antibody test (E-plate; Eiken, Tokyo, Japan), was used for the identification of $H$. pylori-infected participants. The test was conducted at Mitsubishi Chemistry BCL (Tokyo, Japan), where 
Table 1. Helicobacter pylori seropositivity, sex-age-adjusted odds ratios and $95 \%$ confidence intervals for selected sociodemographic factors among Japanese Brazilian children

\begin{tabular}{|c|c|c|c|c|c|}
\hline & $n$ & H. pylori $+^{\mathrm{b}}$ & Percentage & $\mathrm{OR}^{\mathrm{c}}$ & $95 \% \mathrm{CI}^{\mathrm{d}}$ \\
\hline \multicolumn{6}{|l|}{ Age (years) } \\
\hline $0-4$ & 26 & 1 & 3.8 & 1 & Ref. \\
\hline $5-9$ & 125 & 3 & 2.4 & 1 & Ref. \\
\hline $10-14$ & 216 & 19 & 8.8 & 3.89 & $1.29-11.76$ \\
\hline $15-19$ & 140 & 24 & 17.1 & 7.98 & $2.68-23.76$ \\
\hline \multicolumn{6}{|l|}{ Sex } \\
\hline Boys & 265 & 32 & 12.8 & 1 & Ref. \\
\hline Girls & 242 & 15 & 6.2 & 0.45 & $0.23-0.86$ \\
\hline \multicolumn{6}{|l|}{ Family income } \\
\hline$\leq 10$ & 71 & 5 & 7.0 & 1 & Ref. \\
\hline $11-20$ & 123 & 9 & 7.3 & 0.97 & $0.30-3.12$ \\
\hline$>20$ & 286 & 32 & 11.2 & 1.55 & $0.56-4.26$ \\
\hline No answer & 27 & 1 & 3.7 & 0.42 & $0.04-3.92$ \\
\hline \multicolumn{6}{|l|}{ No. of siblings } \\
\hline 0 & 41 & 3 & 7.3 & 1 & Ref. \\
\hline 1 & 271 & 25 & 9.2 & 1.39 & $0.38-5.01$ \\
\hline 2 & 192 & 19 & 9.9 & 1.52 & $0.41-5.60$ \\
\hline$\geq 3$ & 3 & 0 & - & - & - \\
\hline \multicolumn{6}{|l|}{ Parental infection } \\
\hline Father (-) Mother (-) & 201 & 7 & 3.5 & 1 & Ref. \\
\hline Father (+) Mother (-) & 131 & 13 & 9.9 & 2.51 & $0.95-6.61$ \\
\hline Father (-) Mother (+) & 94 & 14 & 14.9 & 4.93 & $1.86-13.06$ \\
\hline Father $(+)$ Mother $(+)$ & 81 & 13 & 16.0 & 5.29 & $1.98-14.14$ \\
\hline Total & 507 & 47 & 9.3 & - & - \\
\hline
\end{tabular}

${ }^{a}$ One monthly income unit based on minimal wage (approximately US\$80)

${ }^{\mathrm{b}}$ Helicobacter pylori seropositivity

${ }^{c}$ Odds ratio

d $95 \%$ Confidence interval

routine measurement of the $\operatorname{IgG}$ antibody has been established.

\section{Statistical analysis}

For assessment of the prevalence of $H$. pylori infection in the study population, we performed analysis in children (0-19 years) and parents (21-69 years) separately. The associations between $H$. pylori seropositivity and risk factors were evaluated by sex-adjusted odds ratios (ORs) and 95\% confidence intervals (95\% CIs). The risk factors were categorized as shown in Tables $1-5$, and significant results were further examined with multiple logistic regression models. These calculations were conducted with the computer program STATA version 7 (STATA, College Station, TX, USA) [22].

\section{Ethical issues}

This study was approved by the Ethics Committee of São Paulo University, School of Medicine, Brazil (Protocol no. 764/01), and the National Ethics CommitteeCONEP, Brazil (Protocol no. 4123).

\section{Results}

The age and sex distributions of the 1037 subjects in the 265 families (507 children and 530 parents) are shown in Tables 1 and 2. Because the numbers of children aged 0-4 years and parents aged 20-29 years were 26 and 5, respectively, these age groups were combined with the older age groups when the ORs were calculated. The ORs indicated that the older age groups had a higher risk of H. pylori infection with the exception of the 60to 69 -year age group (in which there were 4 individuals). Table 1 shows the ORs for $H$. pylori infection in children in relation to age, sex, family income, number of siblings and parents' infection status. The overall seropositivity rate of $H$. pylori infection in children was $9.3 \%$. The seroprevalence of $H$. pylori infection was significantly lower among girls, with an OR of 0.45 (95\% CI, 0.23-0.86). The family income was categorized on the basis of the standard criterion adopted for socioeconomic class in Brazil [23] (1 unit of monthly income $=\mathrm{R} \$ 280$, equivalent to US\$80). There was no difference in the $H$. pylori seropositivity rate between families with 10 units or less of monthly income (7.0\%) 
Table 2. Helicobacter pylori seropositivity, sex-age-adjusted odds ratios and $95 \%$ confidence intervals for selected sociodemographic factors among Japanese Brazilian parents

\begin{tabular}{|c|c|c|c|c|c|}
\hline & $n$ & H. pylori $+^{\mathrm{b}}$ & Percentage & $\mathrm{OR}^{\mathrm{c}}$ & $95 \% \mathrm{CI}^{\mathrm{d}}$ \\
\hline \multicolumn{6}{|l|}{ Age (years) } \\
\hline $21-39$ & 99 & 31 & 31.3 & 1 & Ref. \\
\hline $40-49$ & 338 & 133 & 39.3 & 1.37 & $0.85-2.22$ \\
\hline $50-59$ & 89 & 43 & 48.3 & 1.87 & $1.02-3.43$ \\
\hline $60-69$ & 4 & 1 & 25.0 & 0.65 & $0.06-6.59$ \\
\hline \multicolumn{6}{|l|}{ Sex } \\
\hline Male & 265 & 115 & 43.4 & 1 & Ref. \\
\hline Female & 265 & 93 & 35.1 & 0.74 & $0.52-1.07$ \\
\hline \multicolumn{6}{|c|}{ Family income ${ }^{a}$} \\
\hline$\leq 10$ & 74 & 37 & 50.0 & 1 & Ref. \\
\hline $11-20$ & 120 & 44 & 36.7 & 0.57 & $0.31-1.03$ \\
\hline$>20$ & 307 & 112 & 36.5 & 0.55 & $0.33-0.93$ \\
\hline No answer & 29 & 15 & 51.7 & 1.1 & $0.46-2.61$ \\
\hline \multicolumn{6}{|c|}{ History of stomach diseases } \\
\hline No & 506 & 195 & 38.5 & 1 & Ref. \\
\hline Yes & 24 & 13 & 54.2 & 1.85 & $0.80-4.26$ \\
\hline \multicolumn{6}{|c|}{ Smoking (female) } \\
\hline Never & 193 & 65 & 33.7 & 1 & Ref. \\
\hline Former & 45 & 16 & 35.5 & 1.05 & $0.53-2.08$ \\
\hline Current & 27 & 12 & 44.4 & 1.65 & $0.72-3.75$ \\
\hline \multicolumn{6}{|c|}{ Smoking (male) } \\
\hline Never & 137 & 66 & 48.2 & 1 & Ref. \\
\hline Former & 72 & 27 & 37.5 & 0.65 & $0.36-1.17$ \\
\hline Current & 56 & 22 & 39.3 & 0.70 & $0.37-1.33$ \\
\hline \multicolumn{6}{|c|}{ Alcohol drinking (female) } \\
\hline Never & 180 & 61 & 33.9 & 1 & Ref. \\
\hline Former & 16 & 6 & 37.5 & 1.16 & $0.40-3.36$ \\
\hline Current & 69 & 26 & 37.7 & 1.14 & $0.64-2.05$ \\
\hline \multicolumn{6}{|c|}{ Alcohol drinking (male) } \\
\hline Never & 81 & 39 & 48.1 & 1 & Ref. \\
\hline Former & 23 & 13 & 56.5 & 1.39 & $0.54-3.53$ \\
\hline Current & 161 & 63 & 39.1 & 0.70 & $0.40-1.20$ \\
\hline Total & 530 & 208 & 39.2 & - & - \\
\hline
\end{tabular}

${ }^{a}$ One income unit based on minimal wage (approximately US\$80)

${ }^{\mathrm{b}}$ Helicobacter pylori seropositivity

${ }^{\mathrm{c}}$ Odds ratio

d $95 \%$ Confidence interval

and those with $11-20$ units $(7.3 \%)$. The rate was higher for those with 20 or more units than that for those with less than 20 units $(11.2 \%)$. The H. pylori infection rate increased slightly according to the number of siblings; the OR relative to no siblings was 1.39 (95\% CI, 0.385.01) for those with one sibling, and 1.52 (95\% CI, 0.41-5.60) for those with two siblings. Children with a seropositive mother had a higher risk of $H$. pylori infection; the ORs were 4.93 (95\% CI, 1.86-13.06) with a seronegative father, and 5.29 (95\% CI, 1.98-14.14) with a seropositive father. Children with a seropositive father and a seronegative mother showed an OR of 2.51 (95\% CI, 0.95-6.61). When both father and mother were seronegative, the seroprevalence rate of $H$. pylori infection in children was $3.5 \%$.

Table 2 shows $H$. pylori infection rates according to the characteristics of the parents. The overall seroposi- tive rate of $H$. pylori infection was $39.2 \%$ among adults $-43.4 \%$ for men and $35.1 \%$ for women. In the parents, seropositivity had an inverse association with their income. A positive history of gastrointestinal diseases showed an insignificant elevation of OR $(1.85 ; 95 \%$ CI, $0.80-4.26)$. No associations were found with smoking habit and habitual alcohol drinking for either sex.

Table 3 shows $H$. pylori positivity according to 5 -year age groups and birth order. The H. pylori infection rate increased with age, but there were no significant differences according to birth order among any of the four age groups. Table 4 shows the associations between $H$. pylori seropositivity and living conditions for children. The use of a pacifier and mother's frequent symptoms of nausea and vomiting were associated with an increased risk for H. pylori infection, with ORs of 2.0 (95\% CI, 1.06-3.75) and 20.4 (95\% CI, 3.09-134.88), 


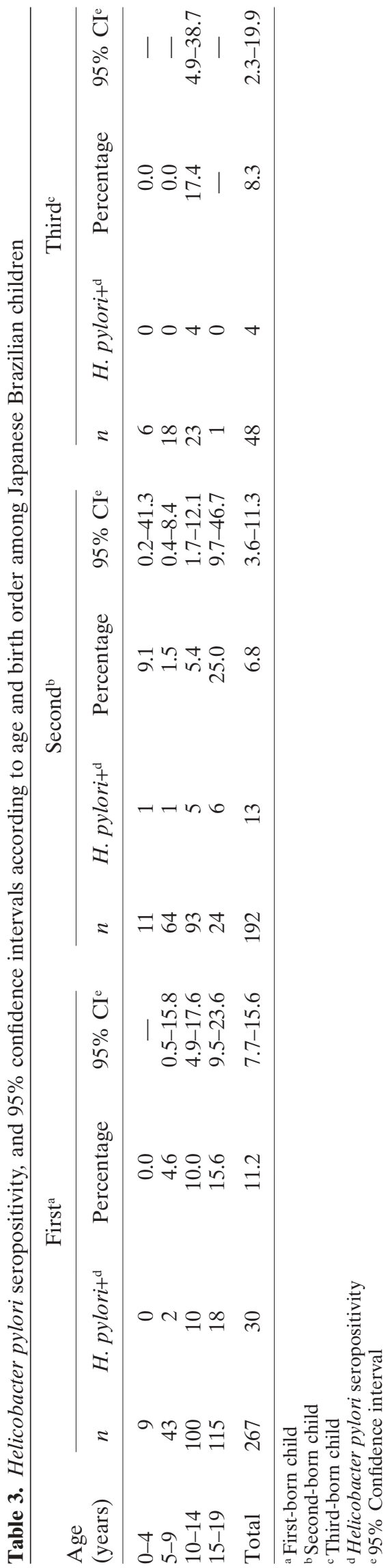

respectively. A child having his/her own room was associated with a reduced risk of infection (OR, 0.44; 95\% CI, 0.23-0.83). We analyzed other factors cited in the methods section, but they were not statistically significant. The significant factors identified by univariate analysis were analyzed with a multivariate logistic regression model (Table 5). Even after adjustment for the listed factors with age, all the significant factors stated above remained statistically significant. We also analyzed other variables (as noted earlier), including type of house and area, frequency of the children sleeping with the mother, number of children sharing the same room, whether parents smoked or consumed alcohol; whether parents cleaned their child after going to the toilet; frequency of pickled vegetable intake in the children, and origin of the child's drinking water, but none was found to be significant (data not shown).

\section{Discussion}

Our serologic study to investigate $H$. pylori infection in healthy families of Japanese descendants living in São Paulo city showed an overall infection prevalence of $9.3 \%$ in children (mean age, 11.5 years). This observed pattern is similar to that reported in developed countries such as Finland [24] and Sweden [25]. The prevalence of $H$. pylori infection among Japanese Brazilian children in our study was much lower than that reported in other studies of children in Brazil. A Brazilian study conducted in a poor rural community in the state of Minas Gerais showed a prevalence of $51.9 \%$ in children with a mean age of 10.1 years [26]. In another study among children living in an urban area from the same state (Minas Gerais), the prevalence was $34.1 \%$ (mean age, 6.4 years) [27]. Children from an urban town in the northeast of Brazil showed a seropositivity rate of $39.3 \%$ (age, $8-11$ years) [28]. Despite the complexity of comparing data from different geographic areas, the data support the concept that improvement in the public environment is associated with a general reduction in the prevalence of $H$. pylori infection in developing regions [11].

The present study was performed in children who were born in an urban setting in a developing country where improvement in sanitation infrastructure is well established. Another explanation for the low prevalence of $H$. pylori in our group is that the participants were volunteers and did not comprise a random sample. Thus, we may have included more individuals with good living conditions that may have influenced $H$. pylori transmission.

Recently, an H. pylori antigen stool test using monoclonal antibodies has shown very promising results, mainly in children and adolescents [29]. In the present 
Table 4. Sex-age-adjusted odds ratios and $95 \%$ confidence intervals of living conditions in childhood for Helicobacter pylori seropositivity among Japanese Brazilian children

\begin{tabular}{|c|c|c|c|c|c|}
\hline & $n$ & H. pylorit ${ }^{\mathrm{a}}$ & Percentage & $\mathrm{OR}^{\mathrm{b}}$ & $95 \% \mathrm{CI}^{\mathrm{c}}$ \\
\hline \multicolumn{6}{|l|}{ Breastfed } \\
\hline Less frequent & 81 & 7 & 8.6 & 1 & Ref. \\
\hline$\geq 6$ months & 426 & 40 & 9.4 & 1.05 & $0.44-2.51$ \\
\hline \multicolumn{6}{|l|}{ Nursing bottle } \\
\hline Less frequent & 107 & 9 & 8.4 & 1 & Ref. \\
\hline$\geq 6$ months & 400 & 38 & 9.5 & 1.05 & $0.48-2.30$ \\
\hline \multicolumn{6}{|l|}{ Premastication of food } \\
\hline No & 428 & 42 & 9.8 & 1 & Ref. \\
\hline$\geq 10$ times & 79 & 5 & 6.3 & 0.81 & $0.30-2.19$ \\
\hline \multicolumn{6}{|l|}{ Pacifier use } \\
\hline No & 341 & 25 & 7.3 & 1 & Ref. \\
\hline Yes & 166 & 22 & 13.2 & 2.00 & $1.06-3.75$ \\
\hline \multicolumn{6}{|c|}{ Pacifier cleaned with mouth } \\
\hline No & 479 & 43 & 8.9 & 1 & Ref. \\
\hline$\geq 10$ times & 28 & 4 & 14.3 & 1.80 & $0.56-5.79$ \\
\hline \multicolumn{6}{|l|}{ Take shower with mother } \\
\hline Less frequent & 449 & 39 & 8.7 & 1 & Ref. \\
\hline Every day & 58 & 8 & 13.8 & 1.72 & $0.73-4.03$ \\
\hline \multicolumn{6}{|l|}{ Had own roon } \\
\hline No & 162 & 22 & 13.7 & 1 & Ref. \\
\hline Yes & 345 & 25 & 7.2 & 0.44 & $0.23-0.83$ \\
\hline \multicolumn{6}{|c|}{ Nausea/vomiting by mother } \\
\hline Never/rare & 501 & 43 & 8.6 & 1 & Ref. \\
\hline Frequently (months) & 6 & 4 & 66.7 & 20.41 & $3.09-134.88$ \\
\hline \multicolumn{6}{|c|}{ Nausea/vomiting by father } \\
\hline Never/rare & 506 & 47 & 9.3 & 1 & Ref. \\
\hline Frequently (months) & 1 & 0 & 0.0 & - & - \\
\hline \multicolumn{6}{|l|}{ Natural food intake } \\
\hline Less frequent & 92 & 7 & 7.6 & 1 & Ref. \\
\hline Every day & 415 & 40.0 & 9.6 & 1.42 & $0.60-3.36$ \\
\hline \multicolumn{6}{|l|}{ Commercial baby food } \\
\hline Less frequent & 491 & 44 & 8.9 & 1 & Ref. \\
\hline Every day & 16 & 3 & 18.7 & 2.55 & $0.65-10.03$ \\
\hline \multicolumn{6}{|l|}{ Fruit intake } \\
\hline Less frequent & 244 & 21 & 8.6 & 1 & Ref. \\
\hline Every day & 263 & 26 & 9.9 & 1.15 & $0.62-2.14$ \\
\hline
\end{tabular}

${ }^{a}$ Helicobacter pylori seropositivity

${ }^{\mathrm{b}}$ Odds ratio

c $95 \%$ Confidence interval

Table 5. Multivariate analysis of living conditions in childhood for Helicobacter pylori seropositivity among Japanese Brazilian children

\begin{tabular}{llc}
\hline & $\mathrm{OR}^{\mathrm{a}}$ & $95 \% \mathrm{CI}^{\mathrm{b}}$ \\
\hline $\begin{array}{l}\text { Sex } \\
\text { Boys }\end{array}$ & 1 & \\
$\quad$ Girls & 0.45 & $0.23-0.89$ \\
Pacifier use & & \\
$\quad$ No & 1 & Ref. \\
$\quad$ Yes & 1.96 & $1.02-3.76$ \\
Had own room & & \\
$\quad$ No & 1 & Ref. \\
$\quad$ Yes & 0.44 & $0.23-0.85$ \\
Nausea/vomiting by mother & & \\
$\quad$ Rare \\
$\quad$ Frequently (months)
\end{tabular}

${ }^{a}$ Odds Ratio adjusted for age and listed factors

b $95 \%$ Confidence interval study, the diagnosis of $H$. pylori infection was performed by serologic testing, as adopted in other studies $[26,27]$. It is reported that this method cannot be applied to young children because of low sensitivity in children below the age 12 years [30]. Furthermore, the use of antibiotics among the children was not determined. If antibiotic use was frequent in this group for the treatment of any kind of infection, this may have influenced the results in the children's group and may, in part, explain the difference in the rate of $H$. pylori seropositivity between the children and their parents.

Information on the prevalence of $H$. pylori infection in São Paulo city is limited. In the study, the prevalence of $H$. pylori infection in the parents, with an average age of 44.5 years, was $39.2 \%$. This frequency is similar to those reported in our previous study with Japanese Brazilian adults [19]. Age was an important risk factor 
for the acquisition of $H$. pylori infection [31]. Our data are consistent with the increase in $H$. pylori prevalence with age, but also showed a decreasing trend in the seropositive rate with birth year among Japanese Brazilians. A study conducted by Tsugane et al. [32] reported an $H$. pylori prevalence rate of $76.8 \%$ for Japanese Brazilians in São Paulo. These data are consistent with the notion that part of the increase in $H$. pylori prevalence noted with age may reflect the relative size of different birth cohorts with marked socioeconomic status difference of the family when the adults were children.

Several studies in various areas have suggested that differences in $H$. pylori prevalence among different groups are associated with socioeconomic status [7,33]. The present study found no significant association with the family income in the children; the $H$. pylori prevalence was, however, inversely related to income in the higher socioeconomic group of the parents. An apparent disadvantage of this population was its sociocultural homogeneity, which reduces the variation in exposure status, thereby decreasing the power of detecting effects in the children's group.

We also analyzed the relationship between $H$. pylori infection, habitual smoking, and alcohol consumption. Previous studies have shown that cigarette smoking or nicotine is a risk factor for $H$. pylori infection [34]. When evaluating cigarette smoking in relation to $H$. pylori infection in the parents, this study, as well as in our previous study [19], we failed to observe any relationship. An association with smoking was reported for Japanese Americans in Seattle [35] and for $294 \mathrm{H}$. pylori-positive Italian volunteer blood donors [36]. There is still no agreement on the role of alcohol consumption, because alcohol is presumed to have both beneficial and adverse effects on $H$. pylori infection, by increasing the permeability of the mucus barrier or augmenting the mucosal defense function [37]. Our study and another with Japanese-Americans [35] did not find any significant association between $H$. pylori infection and alcoholic beverage intake.

One main purpose of the present study was to investigate intrafamilial factors or behaviors associated with $H$. pylori infection. A few studies have shown that a large sibship contributes to infection between siblings, suggesting that infection between siblings may be an infection route [38-40]. We found here that sibship size was positively associated with $H$. pylori infection, though the difference was not significant. The significant inverse association with a child's having her/his own room in our study is also consistent with previous reports which showed that crowded living conditions and sharing a bed were risk factors for $H$. pylori infection [10].

The strong association of $H$. pylori infection in mother and child observed in our study is consistent with findings of other studies indicating person-toperson transmission in families [41-43]. Mothers have a longer and closer contact with their children. By contrast, the role of the father is thought to be minor in terms of the risk of $H$. pylori infection. Less frequent and less intensive contacts with the father may be the reason for the much weaker association with $H$. pylori infection in the child.

The route of transmission of $H$. pylori is subject to ongoing debate. A mother's frequent symptoms of vomiting were significantly associated with $H$. pylori seropositivity. These observations suggested that the oral-oral route plays an important role in the transmission of this disease; this concept is supported by other studies reporting the bacterium in the mouths of a substantial proportion of dyspeptic patients $[44,45]$. The occasional presence of regurgitated gastric juice in the mouth could be a source of $H$. pylori transmission through the premastication of children's food, kisses, checking the milk temperature in the teats of feeding bottles, the common use of spoons or chopsticks, and cleaning a pacifier with the mouth, among others. The presence of the bacteria in the oral cavity in cultures from saliva and dental plaques in dyspeptic patients observed in previous studies support the idea of the transmission of $H$. pylori by mouth [46,47].

During the first few months of pregnancy it is normal for women to feel nausea and to vomit. Therefore, it is possible that an $H$. pylori-positive mother who has many children transmits $H$. pylori to their children during this period, which is consistent with the data that the greater the number of children, the greater is the $H$. pylori prevalence, although a clear difference in seropositivity was found between the youngest child and the elder siblings in our study.

Pacifier use was statistically significant for $H$. pylori infection. The use of pacifiers in children in Brazil is very common. The prevalence was $79 \%$ in children under 2 years [48]. We observed a prevalence of $32.7 \%$ in our cohort of Japanese Brazilian children. In previous studies pacifier use was associated with a higher risk of symptoms such as vomiting, fever, diarrhea, and colic related to inadequate hygiene practices [49].

It was thought that the prevalence of $H$. pylori infection in children whose mothers cleaned the pacifier with their saliva would have been significantly increased as compared with the prevalence in those children whose mothers did not clean the pacifier this way. However, these results were not confirmed on our multivariate analysis. An important methodological issue may be information bias derived from the low positive response rate to this question. So, it possible that discrepancies between the information collected and true behavior led to an underestimation of the strength of the association. 
H. pylori has been isolated from feces [50]; therefore, fecal-oral spread is another possible route of transmission related to inadequate hygiene practices. Furthermore, water contaminated with fecal material has been considered a possible source of transmission [38]. In the current study, the information about the drinking water source or water purification practices showed no association with the acquisition of $H$. pylori infection. The lack of association may be due the high quality of the water consumed daily among the participants; thus, in this study, it was not possible to draw a conclusion.

Another finding of our study was the significantly lower seroprevalence observed in girls compared to boys. These data are consistent with previous studies described by Goodman et al. [38] and Xu et al. [51] and are different from those observed in previous studies in Brazil, where no significant difference in the prevalence of the infection occurs among boys and girls [26,52]. In the present study, data were gathered from a general population of Japanese Brazilians with similar sociocultural levels and environmental conditions. Therefore, we assume that the high activity levels of boys may increase the potential for infection, or that girls play in cleaner surroundings than boys and therefore have a lower risk of exposure from an intradomiciliary source.

In this study, we evaluated risk factors for $H$. pylori infection in children and their parents. The strong evidence that the mother would be the likely source of the H. pylori infection transmitted to her children in this population of Japanese Brazilians suggests that the transmission occurs mainly within the family via close contact with infected individuals. With this knowledge of the high rate of intrafamilial spread, a practical approach would be to improve family hygiene practices, especially when a family member has symptoms of vomiting.

Acknowledgments The authors acknowledge the help of Alice Matsumoto and Tiaki Kawashima, for their fieldwork assistance, Toshiko Saito for her technical assistance, and all communities of Japanese Brazilians.

\section{References}

1. Labenz J, Borsch G. Evidence for the essential role of Helicobacter pylori in gastric ulcer disease. Gut 1994;35:1922.

2. Kuipers EJ, Uyterlinde AM, Pena AS, Roosendaal R, Pals G, Nelis GF, et al. Long-term sequelae of Helicobacter pylori gastritis. Lancet 1995;345:1525-8.

3. Munoz N. Is Helicobacter pylori a cause of gastric cancer? An appraisal of the seroepidemiological evidence. Cancer Epidemiol Biomarkers Prev 1994;3:445-51.

4. Dunn BE, Cohen H, Blaser MJ. Helicobacter pylori. Clin Microbiol Rev 1997;10:720-41.
5. The EUROGAST Study Group. Epidemiology of and risk factors for, Helicobacter pylori infection among 3194 asymptomatic subjects in 17 populations. Gut 1993;34:1672-6.

6. Blecker U, Vanderplas Y. Ethnic differences in Helicobacter pylori infection. Eur J Pediatr 1993;152:377-80.

7. Malaty HM, Evans DG, Evans DJ Jr, Graham DY. Helicobacter pylori in Hispanics: comparison with blacks and whites of similar age and socioeconomic class. Gastroenterology 1992;103:813-6.

8. Blaser MJ, Chyou PH, Nomura A. Age at establishment of Helicobacter pylori infection and gastric carcinoma, gastric ulcer, and duodenal ulcer risk. Cancer Res 1995;55:562-5.

9. Mendall MA, Goggin PM, Molineaux N, Levy J, Toosy T, Strachan D, et al. Childhood living conditions and Helicobacter pylori seropositivity in adult life. Lancet 1992;339:896-7.

10. Galpin OP, Whitaker CJ, Dubiel AJ. Helicobacter pylori infection and overcrowding in childhood. Lancet 1992;339:619.

11. Webb PM, Knight T, Greaves S, Wilson A, Newell DG, Elder J, et al. Relation between infection with Helicobacter pylori and living conditions in childhood: evidence for person to person transmission in early life. BMJ 1994;308:750-3.

12. Mitchell HM, Li YY, Hu PJ, Liu Q, Chen M, Du GG, et al. Epidemiology of Helicobacter pylori in Southern China: identification of early childhood as the critical period for acquisition. J Infect Dis 1992;166:149-53.

13. Goodman KJ, Correa P. Transmission of Helicobacter pylori among siblings. Lancet 2000;355:358-62.

14. Malaty HM, Graham DY, Klein PD, Evans DG, Adam E. Transmission of Helicobacter pylori infection. Studies in families of healthy individuals. Scand J Gastroenterol 1991;26:927-32.

15. Brown LM. Helicobacter pylori: epidemiology and routes of transmission. Epidemiol Rev 2000;22:283-97.

16. Goodman K, Correa P. The transmission of Helicobacter pylori: a critical review of the evidence. Int J Epidemiol 1995;24:875-87.

17. Cave DR. How is Helicobacter pylori transmitted? Gastroenterology 1997;113:S9-S14.

18. Brenner H, Bode G, Adler G, Rothenbacher D. Does maternal smoking hinder mother-child transmission of Helicobacter pylori infection? Epidemiology 2000;11:71-5.

19. Ito LS, Oba SM, Hamajima N, Marie SK, Uno M, Shinjo SK, et al. Helicobacter pylori seropositivity among 963 Japanese Brazilians according to sex, age, generation, and lifestyle factors. Jpn J Cancer Res 2001;92:1150-6.

20. Rocha GA, Queiroz DM, Mendes EN, Oliveira AM, Moura SB, Barbosa MT, et al. Indirect immunofluorescence determination of the frequency of anti-H. pylori antibodies in Brazilian blood donors. Braz J Med Biol Res 1992;25:683-9.

21. Tsugane S, Gotlieb SL, Laurenti R, de Souza JM, Watanabe S. Cancer mortality among Japanese residents of the city of São Paulo, Brazil. Int J Cancer 1990;45:436-9.

22. STATA Corporation. Stata statistical software, release 7.0. College Station, TX: Stata Corporation: 2000.

23. Brazilian Institute of National Statistics and Geography. Censo demográfico, Brasil, 2000. Rio de Janeiro: IBGE, 2002.

24. Ashorn M, Maki M, Hallstrom M, Uhari M, Akerblon HK, Viikari J, et al. Helicobacter pylori infection in Finnish children and adolescents. J Pediatr Gastroenterol Nutr 1999;28:252-6.

25. Tindberg Y, Bengtsson C, Granath F, Blennow M, Nyren O, Grastrom M. Helicobacter pylori infection in Swedish school children: lack of evidence of child-to-child transmission outside the family. Gastroenterology 2001;121:310-6.

26. Rocha GA, Rocha AM, Silva LD, Santos A, Bocewicz AC, Queiroz RM, et al. Transmission of Helicobacter pylori infection in families of preschool-aged children from Minas Gerais, Brazil. Trop Med Int Health 2003;8:987-91.

27. Oliveira AMR, Rocha GA, Moura SB, Rabello ALT, Queiroz DMM. Seroconversion for Helicobacter pylori in adults from Brazil. Trans R Soc Trop Med Hyg 1999;93:261-3.

28. Mitchell A, Silva TM, Barrett LJ, Lima AA, Guerrant RL. Agespecific Helicobacter pylori seropositivity rates of children in an 
impoverished urban area of northeast Brazil. J Clin Microbiol 2003;41:1326-8.

29. Falsafi T, Valizadeh N, Sepehr S, Najafi M. Application of a stool antigen test to evaluate the incidence of Helicobacter pylori infection in children and adolescents from Tehran, Iran. Clin Diagn Lab Immunol 2005;1094-7.

30. Megraud F, European Paediatric Task Force on Helicobacter pylori. Comparison of non-invasive tests to detect Helicobacter pylori infection in children and adolescents: results of a multicenter European study. J Pediatr 2005;146:198-203.

31. Fiedorek SC, Malaty HM, Evans DL, Pumphrey CL, Casteel HB, Evans DJ Jr, et al. Factors influencing the epidemiology of Helicobacter pylori infection in children. Pediatrics 1991;88:57882.

32. Tsugane S, Fahey MT, Hamada GS, Kabuto M, Miyakawa VY. Helicobacter pylori infection and atrophic gastritis in middle-aged Japanese residents of São Paulo and Lima. Int J Epidemiol 1999;28:577-82.

33. Malaty HM, Kim JG, Kim SD, Graham DY. Prevalence of Helicobacter pylori infection in Korean children: inverse relation to socioeconomic status despite a uniformly high prevalence in adults. Am J Epidemiol 1996;143:257-62.

34. Endoh K, Leung FW. Effects of smoking and nicotine on the gastric mucosa: a review of clinical and experimental evidence. Gastroenterology 1994;107:864-78.

35. Namekata T, Miki K, Kimmey M, Fritsche T, Hughes D, Moore $\mathrm{D}$, et al. Chronic atrophic gastritis and Helicobacter pylori infection among Japanese Americans in Seattle. Am J Epidemiol 2000;151:820-30.

36. Russo A, Maconi G, Spinelli P, Felice GD, Eboli M, Andreola S, et al. Effect of lifestyle, smoking, and diet on development of intestinal metaplasia in $H$. pylori-positive subjects. Am J Gastroenterol 2001;5:1402-8.

37. Hook NJ. Effect of alcohol consumption on the risk of Helicobacter pylori infection. Digestion 1991;50:92-8.

38. Goodman KJ, Correa P, Tengana Aux HJ, Ramirez H, DeLany JP, Guerrero Pepinosa O, et al. Helicobacter pylori infection in the Colombian Andes: a population based study of transmission pathway. Am J Epidemiol 1996;3:290-9.

39. Gasbarrini G, Pretolani S, Bonvicini F, Gatto MR, Tonelli E, Megraud F, et al. A population based study of Helicobacter pylori infection in a European country: the San Marino Study. Relations with gastrointestinal diseases. Gut 1995;36:838-44.

40. Kikuchi S, Kurosawa M, Sakiyama T. Helicobacter pylori risk associated with sibship size and family history of gastric diseases in Japanese adults. Jpn J Cancer Res 1998;89:1109-2.
41. Rothenbacher D, Bode G, Berg G, Gommel R, Gonser T, Adler G, et al. Helicobacter pylori among preschool children and their parents: evidence of parent-child transmission. J Infect Dis 1999;179:398-402.

42. Dominici P, Bellentani S, Di Biase AR, Saccoccio G, Le Rose A, Masutti F, et al. Familial clustering of Helicobacter pylori infection: population based study. BMJ 1999;319:537-41.

43. Zhou H, Chan KL, Chu KM, Tam PKH. Intrafamilial spread of Helicobacter pylori: a prospective study using urea breath test. J Pediatr Surg 2000;11:1672-5.

44. Mapstone NP, Lynch DAF, Lewis FA, Axon AT, Tompkins DS, Dixon MF, et al. Identification of Helicobacter pylori DNA in the mouths and stomachs of patients with gastritis using PCR. J Clin Pathol 1993;46:540-3.

45. Mitchell JD, Mitchell HM, Tobias V. Acute Helicobacter pylori infection in an infant, associated with gastric ulceration and serological evidence of intra-familial transmission. Am J Gastroenterol 1992;3:382-6.

46. Czesnikiewicz-Guzik M, Karczewska E, Bielanski W, Guzik TJ, Kapera P, Targosz A, et al. Association of the presence the Helicobacter pylori in oral cavity and the stomach. J Physiol Pharmacol 2004;55:105-15.

47. Pytko-Polonczyk J, Konturek SJ, Karczewska E, Bielanski W, Kaczmarczyk-Stachowska A. Oral cavity as permanent reservoir of Helicobacter pylori and potential source of reinfection. J Physiol Pharmacol 1996;47:121-9.

48. Tomasi E, Victora CG, Post PR, Olinto MT, Behague D. The use of pacifiers in children: fecal contamination and association with diarrhea. Rev Saude Publica 1994;28:373-9.

49. North K, Fleming P, Golding J, the ALSPAC Study Team. Pacifier use and morbidity in the first 6 months of life. Pediatrics 1999;103:e34.

50. Parsonnet J, Shmuely H, Hagerty T. Fecal and oral shedding of Helicobacter pylori from healthy infected adults. JAMA 1999;282:2240-5.

51. $\mathrm{Xu} \mathrm{CD}$, Chen SN, Jiang $\mathrm{SH}, \mathrm{Xu}$ JY. Seroepidemiology of Helicobacter pylori infection among asymptomatic Chinese children. World J Gastroenterol 2000;6:759-61.

52. Rodrigues MN, Queiroz DM, Bezerra Filho JG, Pontes LK, Rodrigues RT, Braga LL. Prevalence of Helicobacter pylori infection in children from an urban community in north-east Brazil and risk factors for infection. Eur J Gastroenterol Hepatol 2004;16: 201-5. 